\title{
Research on Treating Wastewater Containing Heavy Metal by Biological Immobilization
}

\author{
Meng Li, ZHANG Hong-guo*, CHEN Guo-dong, LUO Ding-gui, CHEN \\ Yong-heng
}

School of Environmental Science and Engineering, Guangzhou University; Key Laboratory for Water Quality Security and Protection in Pearl River Delta, Ministry of Education and Guangdong Province, Guangdong Provincial Key Laboratory of radionuclides pollution control and resources Guangzhou, 510006, China

*hgzhang@gzhu.edu.cn

Keywords: bio-immobilized technology, heavy metal, wastewater development

\begin{abstract}
Biological immobilized technology is considered a potential instrument for the removal of heavy metals from waste solutions and for precious heavy metals recovery, an alternative to the conventional processes, such as those based on ion exchange, or adsorption on activated carbon. In this work the state of the art of treating wastewater containing lead, cadmium and chromium and other metals by the method of biological immobilization is presented and results found in literature are compared. It had been demonstrated that heavy metal can be effectively removed by biological immobilization, which had great potential advantages of less cells loss, easily controlling, high efficiency, together with the great economical and environmental merit of recover scarce metal resources.
\end{abstract}

\section{Introduction}

More and more serious heavy metal pollution had been arouse accompanied with the rapid development of industrial modernization. Traditional physicochemical methods are difficult to meet the high standards of metal pollution controlling requirements for their shortcomings of secondary pollutant producing, high running cost and recycling metal resources difficultly.

As a novel method for treating wastewater containing heavy metals, biological immobilized has been given more attention by home and abroad researchers [1]. Immobilization technology refers to enzymes or free of microbial cells being defined or retained in a particular space by chemical or physical methods and kept it active, which can be recycled continually. Compared with these bacteria for removing heavy metals from wastewater not being fixed, the bacteria being immobilized with carrier have the advantages of simple reaction, good stability, high processing efficiency, easy to achieve continuously etc. It have been shown that heavy metals removal by the means of Biological immobilization process are heavily dependent on the surface adsorption of bacteria, the surface adsorption quantity by environmental temperature, the $\mathrm{pH}$ of wastewater, dose of adsorbent, initial concentration of metal ions, strength and performance of immobilized material and so on. This paper aimed to provides an overview of the state of the art of treating wastewater containing heavy metals by the method of biological immobilization in order to promoting the awareness and research in this area.

\section{Removal of lead}

Metallic lead in wastewater if not be treated will be enriched through the food chain to the human body, then leading to the human digestive and nervous system have great harm.

As early as 2002, Liu YY [2] and others went on immobilized bacillus licheniformis R08 adsorption removal of lead ion research. The results of the study show that, the polyvinyl alcohol and sodium alginate as embedding agent immobilized bacillus licheniformis R08 bacteria for lead ions the saturated adsorption amount can reach $86.6 \mathrm{mg} / \mathrm{g}$, immobilized adsorption process in line with the Langmuir and Freundlich equation. 
In 2011, Kumar S [3] and others investigated the biosorption property of Streptomyces VITSVK5 spp by absorbing heavy metals lead in the wastewater. The research show that biomass had better adsorption effect, the $\mathrm{pH}$ of 5 in aqueous solution, biomass reached the maximum adsorption of lead ions. When the $\mathrm{pH}$ in wastewater is higher, due to the formation of metal ions soluble hydroxyl compounds, lead ions adsorption capacity gradually weakened.

In 2012, Zhang F [4], who studied strontium hydroxyapatite nanorods fixed highly acidic wastewater lead. In the wastewater the $\mathrm{pH}$ is 2 , the temperature of $30{ }^{\circ} \mathrm{C}$, the immobilization of lead ions reach equilibrium in $15 \mathrm{~min}$, and the fixed quantity reach $1482 \pm 137 \mathrm{mg} / \mathrm{g}$, much more than most of the report [5].

\section{Removal of cadmium}

The major sources of cadmium in the environment is the production and use of alloys, electroplating and pesticides. Cadmium can be transformed to the human body through food chain, causing damage to the human liver, kidney disorders, hypertension and so on.

In 2010, Mao HX [6] and others studied fixed Rhodobacter sphaeroides to remove cadmium ions and chromium ions in wastewater. Experiment on removal of cadmium is conducted on Rhodobacter sphaeroides biomass show $96.68 \%$ removal efficiency, and the adsorption performance of immobilized cell for cadmium ion is far greater than the free bacteria.

In 2011, Divya B [7] and others studied modified Achromobacter removal of cadmium ions in wastewater. Studies are conducted on modified Achromobacter and its removal efficiency can reach $85 \%$. With cadmium ion initial concentration increasing, medium toxicity increasing, leading to a gradual reduction in bacterial biomass accumulation of heavy metals, cadmium ion removal rate decreased continuously.

In 2013, Sarat BI [8] and others studied that adsorptions of cadmium ions from wastewater using marine yeast biomass of Yarrowia lipolytica. The research results show that the $\mathrm{pH}$ of the wastewater is 6 , as ligand of positively charged ions and metal ion exchange, the adsorption amount of cadmium reach the maximum. When biomass dose increase gradually in the solution, the metal binding sites also increase, the metal ions adsorption capacity increase gradually.

\section{Removal of chromium}

Chromium is an essential trace element in human body, if hexavalent chromiun in human body exceed the limits of human endurance, which can cause respiratory tract, liver and kidney disease even death.

In 2009, Zhang S [9] and others who studied the adsorption of chromium ions of immobilized waste beer yeast in wastewater. The results show that $1 \%$ gelatin and $2 \%$ sodium alginate entrapped yeast beer with higher adsorption rate of chromium ion. After the adsorbent is eluted with hydrochloric acid, parse rate of $93.6 \%$, can be reused. Under the optimum adsorption conditions, chromium ion adsorption rate is $96.8 \%$.

In 2011,research had been carried out by Chen GQ [10] by the method of chemical modified Phanerochaete Chrysosporium processing chromium ion in wastewater. When the $\mathrm{pH}$ of wastewater is 3 , after cell surface modification increase more adsorption sites, so that reducing the hydrogen ions and metal ions of competition, making the chromium ion adsorption reach $283.05 \mathrm{mg} / \mathrm{L}$.

In the same year, Zhao CQ [11] and others who studied powdered activated carbon as entrapping agents, embedding Bacillus cereus and made of immobilized cell particles adsorption of chromium in Tannery Wastewater. Under the condition of the optimal treatment of chrome tanning wastewater, immobilized bacteria than the pure Bacillus cereus and without bacteria fixed particle have a better removal effect, the maximum removal rate of chromium ions can reach $99.19 \%$. 


\section{Conclusions}

Because of its unique advantages, Biological immobilization technology has attracted widespread concern in the field of metal wastewater treatment. Single metal in wastewater being treated by biological immobilized technology has become more and more mature. However the technology is still in the laboratory stage, there still a long way for the application and production. Moreover, there are a variety of metals in wastewater, it is more difficult than removing wastewater containing single metal. More strict experiments should be carried through to verify the effective and efficiency of removing wastewater containing complex compositions. By conducting much deeper research, biological immobilization technology will become more and more improvement, which would play a more important role in the area of treating wastewater containing heavy metals.

\section{Acknowledgements}

The investigation is supported by National Natural Science Foundation (51208122), Department of Science and Technology of Guangdong Province (2010B0309 00008) and New Technological Star Project of Pearl River.

\section{References}

[1] Yang PY,Wang ML.Packed-Entrapped-Mixed microbial cells for small wastewater treatment[J].Water and Science Technology.22(3):343-350(1990)

[2] Liu YY,Li RZ,Zhang XL,et al.Study on the immobilization of Bacillus licheniformis R08 adsorption $\mathrm{Pd}^{2+}[\mathrm{J}]$.Journal of Microbiology,42(6):700-705(2002)

[3] Kumar S,Krishnan K.Biosorption of $\mathrm{Cd}(\mathrm{II})$ and $\mathrm{Pb}(\mathrm{II})$ Ions by Aqueous Solution of Novel Alkalophillic Strepttomyces VITSVK5 spp. Biomass[J].Oceanic and Coastal Sea Research,10(1): 61-66(2011)

[4] Zhang F,Zhao ZS,Tan RQ,et al.Efficient and selective immobilization of Pb2+ in highly acidic wastewater using strontium hydroxyapatite nanorods[J].Chemical Engineering Journal,203: 110-114(2012)

[5] Lee S,An JS,Kim YJ,et al.Binging stength-associated toxicity reduction by birnessite and hydroxyapatite in $\mathrm{Pb}$ and $\mathrm{Cd}$ contaminated sediments[J].Journal of Hazardous Materials, 186:2117-2122(2011)

[6] Mao XH,Xu MF,Liu H,et al.Study on immobilization of Rhodobacter sphaeroides treatment of $\mathrm{Cd}$ and $\mathrm{Cr}$ in electroplating wastewater[J].Journal of ecology and rural environment,26(2): 160-166(2010)

[7] Divya B,Rajender K,Rajesh S,et al.Statistical modelling and optimization of substrate composition for bacterial growth and cadimum removal using response surface methodology[J]. Ecological Engineering,37:2076-2081(2011)

[8] Sarat BI,Ramakrishna C,Silas S,et al.Application of Doehlert experimental design for the optimization of cadmium biosorption in an aqueous solution by marine yeast biomass of Yarrowia lipolytica[J].Korean Journal Chemical Engineering,30(5):1067-1075(2013)

[9] Zhang S,Cheng H.Immobilized beer waste yeast adsorption of Cr (VI)[J].Journal of environmental engineering,3(3):489-492(2009)

[10] Chen GQ,Zhang WJ,Zeng GM,et al.Surface-modified Phanerochaete chrysosporium as a biosorbent for $\mathrm{Cr}(\mathrm{IV})$-contaminated wastewater[J].Journal of Hazardous Materials,186(2-3): 2138-2143(2011) 
[11] Zhao CQ,Chen WY,Yang QH.Immobilization of Bacillus cereus treated Cr (VI) in tannery wastewater Optimization[J].Journal of Sichuan University of Science and Engineering. 24(4): 436-439(2011) 